\title{
Enfermagem e epidermólise bolhosa: concepção sobre a doença genética: revisão integrativa
}

\begin{abstract}
A Epidermólise Bolhosa (EB) hereditária é uma doença secundária a mutações de genes responsáveis pela formação de proteínas que permitem a coesão entre as diferentes camadas da pele. O trabalho tem como objetivo compreender a causalidade da Epidermólise bolhosa vinculado a concepção da enfermagem frente a essa doença crônica. Trata-se de uma pesquisa bibliográfica, do tipo revisão integrativa, em que foram selecionadas algumas bases de dados para serem utilizados para a busca, que foram: Scientific Eletronic Library Online (SCIELO) e na Literatura Latino-Americana e do Caribe em Ciências da Saúde (LILACS) e Base de Dados da Enfermagem (BDENF). A principal característica da EB é o surgimento de feridas crônicas na pele que geralmente são pequenas, numerosas, dolorosas, desconfortáveis e com grande quantidade de exsudato. Perceberam-se que, os enfermeiros, geralmente, são empáticos diante dos pacientes, reconhecendo e compreendendo o sofrimento vivenciado por estes, bem como pelos cuidadores. Ressalta-se, ainda, o fato de os enfermeiros generalistas apresentarem dificuldades em tratar um paciente com EB, pois se sentem despreparados frente às necessidades que a patologia exige. Portanto, a avaliação precoce da ferida e o manejo adequado de tratamento são os pilares do cuidado a esses pacientes. O uso dessa prática medicinal no tratamento de feridas apresenta vários efeitos satisfatórios, entretanto há necessidade de mais estudos para garantir uma prática mais segura.
\end{abstract}

Palavras-chave: Epidermólise Bolhosa; Enfermagem; Doença Genética.

\section{Nursing and bullous epidermolysis: conception of genetic disease: integrative review}

\begin{abstract}
Hereditary Epidermolysis Bullosa (EB) is a disease secondary to gene mutations responsible for the formation of proteins that allow cohesion between different layers of the skin. The objective of this study is to understand the causality of epidermolysis bullosa linked to the conception of nursing regarding this chronic disease. This is a bibliographic research, of the integrative review type, in which some databases were selected to be used for the search, which were: Scientific Electronic Library Online (SCIELO) and Latin American and Caribbean Literature on Health (LILACS) and Nursing Database (BDENF). The main characteristic of EB is the appearance of chronic skin wounds that are usually small, numerous, painful, uncomfortable and with a large amount of exudate. It was noticed that nurses are generally empathic towards patients, recognizing and understanding the suffering experienced by them, as well as by caregivers. Also noteworthy is the fact that generalist nurses have difficulties in treating a patient with EB, because they feel unprepared before the needs that the pathology demands. Therefore, early wound assessment and proper management of treatment are the cornerstones of care for these patients. The use of this medicinal practice in the treatment of wounds has several satisfactory effects, but further studies are needed to ensure a safer practice.
\end{abstract}

Keywords: Bullous Epidermolysis; Nursing; Genetic disease.

Topic: Enfermagem Pediátrica

Reviewed anonymously in the process of blind peer

Wellington Pereira Rodrigues (D)

Centro Universitário AGES, Brasil

http://lattes.cnpq.br/2798105983752891

http://orcid.org/0000-0002-0993-6871

wellington life@live.com

Priscila Dantas Gonçalves (iD

Centro Universitário AGES, Brasil

http://lattes.cnpq.br/7078066094809493

http://orcid.org/0000-0002-1849-0226

prisciladantasg@hotmail.com

Cinthia Caldas Rios Soares (ii)

Centro Universitário de Muriaé, Brasil

http://lattes.cnpq.br/7524534278738838

http://orcid.org/0000-0001-5596-0007

renansallazar@gmail.com
Received: 07/03/2019

Approved: 08/05/2019

\author{
Leonardo Fabrício Gomes Soares (iD) \\ Universidade Federal de Minas Gerais, Brasil \\ http://lattes.cnpq.br/8378350632989308 \\ http://orcid.org/0000-0002-4043-5557 \\ renansallazar@gmail.com \\ Renan Sallazar Ferreira Pereira \\ Universidade Federal do Amazonas, Brasil \\ http://lattes.cnpq.br/8154326371029706 \\ http://orcid.org/0000-0001-5140-4046 \\ renansallazar@gmail.com \\ Ana Paula Gomes Soares (D) \\ Universidade Federal de Viçosa, Brasil \\ http://lattes.cnpq.br/3631825469916595 \\ http://orcid.org/0000-0002-1050-6035 \\ anapaulagsoares@yahoo.com.br
}

Referencing this:

RODRIGUES, W. P.; GONÇALVES, P. D.; SOARES, C. C. R.; SOARES, L. F. G.; PEREIRA, R. S. F.; SOARES, A. P. G.. Enfermagem e epidermólise bolhosa: concepção sobre a doença genética: revisão integrativa. Scire Salutis, v.9, n.2, p.19-26, 2019. DOI:

http://doi.org/10.6008/CBPC2236-9600.2019.002.0003 


\section{INTRODUÇÃO}

A Epidermólise Bolhosa (EB) hereditária é uma doença secundária a mutações de genes responsáveis pela formação de proteínas que permitem a coesão entre as diferentes camadas da pele. É caracterizada pelo aparecimento de bolhas e lesões na pele e nas membranas mucosas espontaneamente ou como resposta a traumatismos mínimos. Existem muitas formas, de acordo com o nível (profundidade) da pele em que ocorre a deficiência de coesão. A classificação da EB inclui também o modo hereditário de transmissão da doença: autossómico dominante ou recessivo (SILVA, 2014).

A EB é uma das mais complexas doenças conhecidas, com implicações devastadoras nos subtipos mais severos, com reduzida qualidade e esperança de vida. Esta patologia é o paradigma de uma doença órfã. A sua raridade explica a falta de conhecimentos científicos e médicos, a escassez de investimento na investigação e desenvolvimento de fármacos e a inexistência de legislação, o que culmina em cuidados de saúde inadequados e na exclusão social, económica, profissional e cultural (MARGARITA et al., 2010).

Sendo atualmente uma doença sem cura, os cuidados de suporte no tratamento das feridas e reconhecimento precoce de complicações são essenciais no tratamento do doente com EB. Os principais tipos de complicações são a sobre infecção bacteriana seguida de sepses (causa frequente de morte no período neonatal), a cicatrização deformante e o aparecimento de neoplasias cutâneas agressivas (causa mais frequente de mortalidade a partir da adolescência) (CUESTA, 2013).

O trabalho tem como objetivo compreender a causalidade da Epidermólise bolhosa vinculado a concepção da enfermagem frente a essa doença crônica. Foi demonstrado que devido à fragilidade da pele nestes pacientes o uso de alguns curativos fica restringido. $O$ tratamento de feridas em EB apresenta desafios únicos: a variabilidade na apresentação clínica requer um plano de tratamentos individualizado, a variedade de produtos disponível dificulta a escolha do tratamento mais adequado e os custos elevados inerentes aos tratamentos têm um peso económico elevado sobre as famílias e unidades de cuidados de saúde (GROCOTT et al., 2013).

\section{MATERIAIS E MÉTODOS}

Trata-se de uma pesquisa bibliográfica do tipo revisão integrativa, em que foram selecionadas algumas bases de dados para serem utilizados para a busca, que foram: Scientific Eletronic Library Online (SCIELO) e na Literatura Latino-Americana e do Caribe em Ciências da Saúde (LILACS) e Base de Dados da Enfermagem (BDENF).

Em seguida foram utilizados os seguintes critérios de inclusão dos estudos: textos completos, estudos primários, realizados no período de 2010 a 2015, com humanos, nos idiomas português e espanhol. Depois foi realizada leitura analítica dos títulos e resumos e toda a bibliografia selecionada para ordenar as informações e identificar os objetos de estudo. O passo seguinte foi leitura exploratória e interpretativa das publicações, com a finalidade de ressaltar as principais ideias consideradas para essa revisão. 
Para extração dos dados, elaborou-se e adotou-se um instrumento contemplando as variáveis: procedência, título do artigo, autores, ano, tipo de estudo e temática. As temáticas foram agrupadas conforme semelhança de conteúdo para serem discutidas em seguida. Ao todo foram selecionados 7 artigos para análise.

\section{RESULTADOS E DISCUSSÃO}

A gravidade e extensão das lesões na pele e o envolvimento de outros órgãos mucocutâneos variam consideravelmente entre os tipos de EB, e é em grande parte determinada pela natureza das mutações e pela penetração do gene resultando em expressões fenotípicas diferentes. Existem vários tipos de epidermólise bolhosa, sempre relacionado ao tipo de estrutura comprometida. No grupo da epidermólise bolhosa simples, existem quatro subtipos clínicos: Weber, Cackayne, Koebner, Dowling Meara.

Há, também, a epidermólise bolhosa simples com distrofia muscular tardia. Na epidermólise bolhosa simples, as lesões são resultadas da intensa degeneração das células basais da epiderme por alteração da queratina, determinada por mutação cromossômica. Esta variedade de epidermólise não deixa cicatrizes nem provoca alterações ungueais ou dentárias (WRIGHT, 2010).

Já na epidermólise bolhosa juncional, a clivagem situa-se na junção dermoepidérmica, na lâmina lúcida da zona da membrana basal. Esta variação produz efeitos graves, com ocorrência de anemia, sinéquias, retardo de crescimento, disproteinemia, alopecia cicatricial, hiperqueratose palmoplantar, podendo ser fata. A epidermólise bolhosa distrófica pode ter herança dominante ou recessiva. Na dominante, a clivagem é dermoepidérmica abaixo da lâmina densa da zona da membrana basal. Clinicamente, as unhas podem apresentar-se distróficas ou ausentes, havendo também a presença de máculas hipocrômicas e atróficas (lesões albo-papuloide), milias, cicatrizes hipertróficas e comprometimento bucal leve.

$\mathrm{Na}$ epidermólise bolhosa distrófica recessiva, a clivagem é dermoepidérmica com defeito na estrutura do colágeno VII e na liberação celular do colágeno sintetizado. Trata-se de uma forma grave da enfermidade, em que o paciente, geralmente, não atinge a idade adulta. Essa forma leva ao surgimento de sinéquias nos pés e mãos com inutilidade funcional, estenose esofageana, provocando anemia, retardo do crescimento, dentes displásicos e cicatrizes atróficas no couro cabeludo (GROCOTT et al., 2013).

Um aspecto que tem merecido progressiva atenção é a avaliação e o suporte nutricional. $\mathrm{Na}$ puberdade, período de maior exigência nutricional, se a suplementação não for suficiente, a alimentação por gastrostomia pode ser necessária, para complementar a alimentação oral (SPRECHER, 2010). Esta condição também pode ser um valioso instrumento de administração medicamentosa, especialmente quando o paciente necessita de tipos variados de preparações, que dificultam a ingestão pela necessidade de um volume significativo de líquido. No quadro 1, têm-se as abordagens referenciais sobre o assunto.

A principal característica da EB é o surgimento de feridas crônicas na pele que geralmente são pequenas, numerosas, dolorosas, desconfortáveis e com grande quantidade de exsudato. Tais sintomas foram citados como infortúnios no cotidiano dos pacientes que vivenciam esta condição. Dessa forma, o cuidado das feridas é a base do tratamento para pacientes com EB. No entanto, atualmente, não há diretrizes 
específicas que contribuam para o cuidado dos profissionais com esses pacientes. Os profissionais que trabalham diretamente com esse público afirmam a necessidade de um trabalho mais planejado e organizado, pois assim facilitar-se-á a qualidade do cuidado na tomada de decisões (TOSTI, 2010).

Quadro 1: Abordagens referenciais.

\begin{tabular}{|c|c|c|c|c|c|c|}
\hline $\begin{array}{c}\text { Bases de } \\
\text { dados }\end{array}$ & Título & Autores & $\begin{array}{c}\text { Ano de } \\
\text { publicação }\end{array}$ & $\begin{array}{l}\text { Método } \\
\text { aplicado }\end{array}$ & País & Resultados \\
\hline $\begin{array}{c}\text { International } \\
\text { Wound Journal }\end{array}$ & $\begin{array}{l}\text { Um consenso abordagem } \\
\text { para ferida cuidado na } \\
\text { epidermólise bullosa. }\end{array}$ & $\begin{array}{l}\text { GROCOTT } \\
\text { et al. }\end{array}$ & 2013 & $\begin{array}{l}\text { Revisão } \\
\text { Sistemática da } \\
\text { Literatura. }\end{array}$ & $\begin{array}{c}\text { Nacional/ } \\
\text { Internacional }\end{array}$ & $\begin{array}{l}\text { Um significante número de } \\
\text { limitações foi encontrado em } \\
\text { relação à utilização de } \\
\text { coberturas. Aquelas que } \\
\text { deveriam ser utilizadas para } \\
\text { cobrir apenas uma ferida eram } \\
\text { usadas para cobrir feridas } \\
\text { extensas e múltiplas. }\end{array}$ \\
\hline $\begin{array}{l}\text { Orphanet } \\
\text { Journal of Rare } \\
\text { Diseases }\end{array}$ & $\begin{array}{l}\text { Diacereína tópica para } \\
\text { epidermólise bullosa: um } \\
\text { randomizado piloto } \\
\text { controlado estude. }\end{array}$ & $\begin{array}{l}\text { WALLY } \\
\text { et al. }\end{array}$ & 2013 & $\begin{array}{l}\text { Ensaio Clínico } \\
\text { Controlado } \\
\text { Aleatório Nível } \\
\text { II. }\end{array}$ & $\begin{array}{c}\text { Nacional/ } \\
\text { Internacional }\end{array}$ & $\begin{array}{l}\text { A aplicação de diacereína (1\%) } \\
\text { pode diminuir } \\
\text { significativamente a formação } \\
\text { de bolhas em até duas } \\
\text { semanas. }\end{array}$ \\
\hline $\begin{array}{l}\text { Journal of the } \\
\text { American } \\
\text { Academy of } \\
\text { Dermatology }\end{array}$ & $\begin{array}{l}\text { Um consenso } \\
\text { abordagem para ferida } \\
\text { cuidado na epidermólise } \\
\text { bullosa }\end{array}$ & POPE et al. & 2012 & $\begin{array}{l}\text { Analítico Nível } \\
\text { V. }\end{array}$ & $\begin{array}{c}\text { Nacional/ } \\
\text { Internacional }\end{array}$ & $\begin{array}{l}\text { Recomendações específicas } \\
\text { para o tratamento da EB } \\
\text { poderão fornecer aos } \\
\text { profissionais uma orientação de } \\
\text { como cuidar dos pacientes com } \\
\text { EB. }\end{array}$ \\
\hline $\begin{array}{c}\text { Journal of } \\
\text { Wound Care }\end{array}$ & $\begin{array}{l}\text { O psicossocial } \\
\text { impacto de doenças } \\
\text { crônicas feridas em } \\
\text { pacientes com } \\
\text { epidermólise bolhosa. }\end{array}$ & ADNI et al. & 2012 & $\begin{array}{l}\text { Pesquisa } \\
\text { Bibliográfica. }\end{array}$ & $\begin{array}{c}\text { Nacional/ } \\
\text { Internacional }\end{array}$ & $\begin{array}{l}\text { Pacientes com EB carecem de } \\
\text { uma atenção multidisciplinar } \\
\text { que não se limite apenas ao } \\
\text { controle da dor, mas que } \\
\text { abranja os aspectos } \\
\text { psicossociais dos pacientes }\end{array}$ \\
\hline $\begin{array}{c}\text { International } \\
\text { Wound Journal }\end{array}$ & $\begin{array}{l}\text { Co-produtor } \\
\text { ferida nova produtos } \\
\text { para cuidados para } \\
\text { epidermólise bullosa; um } \\
\text { empírico estudo de caso } \\
\text { do uso de substitutos no } \\
\text { design e protótipo } \\
\text { processo de } \\
\text { desenvolvimento. }\end{array}$ & $\begin{array}{l}\text { GROCOTT } \\
\text { et al. }\end{array}$ & 2014 & Descritivo. & $\begin{array}{c}\text { Nacional/ } \\
\text { Internacional }\end{array}$ & $\begin{array}{l}\text { Há limitações nos curativos } \\
\text { atuais para as feridas oriundas } \\
\text { da EB, especialmente quando } \\
\text { se trata de tamanho, } \\
\text { estabilidade, } \\
\text { temperatura e controle de } \\
\text { exsudato. }\end{array}$ \\
\hline Chronic Illness & $\begin{array}{l}\text { 'Você é o que for } \\
\text { necessidades do paciente } \\
\text { no time': o impacto } \\
\text { sobre saúde e social } \\
\text { profissionais de cuidados } \\
\text { de apoiando pessoas com } \\
\text { epidermólise } \\
\text { bullosa. }\end{array}$ & $\begin{array}{l}\text { DURES } \\
\text { et al }\end{array}$ & 2010 & $\begin{array}{l}\text { Estudo } \\
\text { quantitativo } \\
\text { descritivo } \\
\text { longitudinal. } \\
\text { Nível V. }\end{array}$ & $\begin{array}{c}\text { Nacional/ } \\
\text { Internacional }\end{array}$ & $\begin{array}{l}\text { O bem-estar de profissionais de } \\
\text { saúde que lidam com pacientes } \\
\text { com EB pode ser afetado } \\
\text { negativamente devido à } \\
\text { carência de profissionais } \\
\text { especialistas em EB; e a } \\
\text { preocupação com o estado de } \\
\text { saúde do paciente }\end{array}$ \\
\hline $\begin{array}{c}\text { Journal of } \\
\text { Investigative } \\
\text { Dermatology }\end{array}$ & $\begin{array}{l}\text { Desenvolvimento de } \\
\text { siRNA terapêutico } \\
\text { específico de alelo para } \\
\text { mutações da queratina } 5 \\
\text { na epidermólise bolhosa } \\
\text { simplex. }\end{array}$ & $\begin{array}{l}\text { ATKINSON } \\
\text { et al. }\end{array}$ & 2011 & $\begin{array}{l}\text { Estudo } \\
\text { quantitativo } \\
\text { descritivo } \\
\text { exploratório. }\end{array}$ & $\begin{array}{c}\text { Nacional/ } \\
\text { Internacional }\end{array}$ & $\begin{array}{l}\text { O RNA interference pode atuar } \\
\text { seletivamente, silenciando } \\
\text { alelo mutante, que é um dos } \\
\text { fatores responsáveis pelas } \\
\text { feridas. }\end{array}$ \\
\hline $\begin{array}{l}\text { British Journal } \\
\text { of } \\
\text { Dermatology }\end{array}$ & $\begin{array}{l}\text { Impacto do herdado } \\
\text { epidermólise } \\
\text { bullosa no parental } \\
\text { interpessoal relação, } \\
\text { estado civil e tamanho } \\
\text { família. }\end{array}$ & FINE et al. & 2015 & & $\begin{array}{c}\text { Nacional/ } \\
\text { Internacional }\end{array}$ & $\begin{array}{l}\text { A presença de uma criança com } \\
\text { EB pode afetar negativamente } \\
\text { a sua família. Isso ocorre em } \\
\text { função da necessidade de } \\
\text { cuidados intensivos com as } \\
\text { feridas da criança. }\end{array}$ \\
\hline
\end{tabular}

Além disso, identificou-se a dificuldade que tais profissionais têm em se desvincular afetivamente dos pacientes, uma vez que se sentem aflitos e tristes com a situação deles. Percebeu-se que os enfermeiros, geralmente, são empáticos diante dos pacientes, reconhecendo e compreendendo o sofrimento vivenciado por estes, bem como pelos cuidadores. Essa situação afeta a qualidade de vida do profissional e dificulta o 
equilíbrio entre trabalho e vida social. Consequentemente, isso interfere na forma do cuidado (INTONG, 2012).

Aumentando a investigação sobre curativos atraumáticos que diminuem a dor e danos, ao leito, da ferida, levando ao desenvolvimento de curativos atraumáticos, não aderentes à base de silicone medicinal. Algumas formas de EB apresentam manifestações como bolhas no palato, língua, assoalho bucal, lábios, além de displasias dentárias e microstomias (GROCOTT et al., 2013).

Complicações extracutâneas, frequentemente, requerem atendimento sob anestesia regional ou geral, sendo necessários cuidados pré e pós-operatórios, de modo que a anestesia não agrave as limitações já existentes. Para o sucesso de qualquer procedimento cirúrgico, exige-se a presença de uma equipe cirúrgica multidisciplinar qualificada, a fim de proporcionar $\mathrm{o}$ ato anestésico seguro com poucas complicações, e minimizando os danos na pele e na mucosa. Todo instrumento que entra em contato com o paciente (máscara facial, laringoscópio e tubos endotraqueais), deve estar bem lubrificado. Gazes lubrificadas estão indicadas para fixar os eletrodos para monitorização cardíaca, esfigmomanômetro e acessos venosos (BRUCKNER-TUDERMAN, 2010).

Nos dentes, as alterações vêm sendo descritas como deformidades, defeitos congênitos e formação anormal de esmalte. Dentes impactados e supranumerários também são muito comuns. Cáries extensas, escarificação dos tecidos periodontais e abscessos vêm sido relatados. O osso alveolar reabsorve e o palato e o assoalho se tornam contínuos com o vestíbulo bucal. Frequentemente o movimento da língua é afetado como resultado das cicatrizes (WALLY et al., 2013).

A principal característica da EB é o surgimento de feridas crônicas na pele que geralmente são pequenas, numerosas, dolorosas, desconfortáveis e com grande quantidade de exsudato. Tais sintomas foram citados como infortúnios no cotidiano dos pacientes que vivenciam esta condição. Dessa forma, o cuidado das feridas é a base do tratamento para pacientes com EB. No entanto, atualmente, não há diretrizes específicas que contribuam para o cuidado dos profissionais com esses pacientes. Os profissionais que trabalham diretamente com esse público afirmam a necessidade de um trabalho mais planejado e organizado, pois assim facilitar-se-á a qualidade do cuidado na tomada de decisões (ADNI et al., 2012).

Além disso, identificou-se a dificuldade que tais profissionais têm em se desvincular afetivamente dos pacientes, uma vez que se sentem aflitos e tristes com a situação deles. Percebeu-se que os enfermeiros, geralmente, são empáticos diante dos pacientes, reconhecendo e compreendendo o sofrimento vivenciado por estes, bem como pelos cuidadores. Essa situação afeta a qualidade de vida do profissional e dificulta o equilíbrio entre trabalho e vida social. Consequentemente, isso interfere na forma do cuidado (POPE et al., 2012).

Ressalta-se, ainda, o fato de os enfermeiros generalistas apresentarem dificuldades em tratar um paciente com EB, pois se sentem despreparados frente às necessidades que a patologia exige. Com isso, os pacientes relataram não sentir confiança nos profissionais que não eram especialistas em EB e, muitas vezes, relutaram receber assistência deles. Essa situação pode ser considerada um problema, tendo em vista que 
os profissionais especialistas são escassos e os pacientes com EB necessitam de cuidados contínuos (DURES et al., 2010).

A raridade da doença gera uma carga de ansiedade aos profissionais, resultando em uma situação de incapacidade frente às atividades de assistência em enfermagem. Assim, os enfermeiros têm dificuldade em realizar o cuidado, por este ser muitas vezes extensivo, complicado e não gerar tantos resultados positivos em função da EB ser incurável. Esta realidade provoca um sentimento de incompetência, frustração e culpa, devido à impressão de que a assistência não está possibilitando benefícios, nem sendo impactante ou significativa na vida dos pacientes (ATKINSON et al., 2011).

A depressão também é uma ocorrência comum entre os pacientes mais gravemente afetados pela epidermólise bolhosa, e a sua frequência aumenta com a idade, pela percepção alterada da imagem corporal e ao aumento das deformidades nas extremidades, o que os torna cada vez mais incapacitados para suas atividades, com presença de dores crônicas e piora na cicatrização das feridas. $\mathrm{O}$ impacto emocional atinge também seus pais, membros da família, amigos e cônjuges. 0 médico psiquiatra e o assistente social são importantes componentes da assistência global destes pacientes. Quando criteriosamente escolhidos e empregados, alguns antidepressivos podem amenizar a dor e a coceira, melhorando o humor, o sono e proporcionando uma sensação de bem-estar (WALLY et al., 2013).

Os enfermeiros que lidam diretamente com os pacientes com EB perceberam a quão multifacetada é a assistência, pois requer cuidados médicos, psicossociais e práticos. Por isso, a equipe deve trabalhar de forma harmoniosa e integrada para, então, obter êxito no tratamento (FINE et al., 2015). Uma pesquisa, que elaborou planos de abordagem ao paciente com EB por meio de entrevistas com a equipe multiprofissional, identificou que, para o cuidado adequado aos pacientes, é indispensável o desenvolvimento de uma terapia de relacionamento. Esta deve envolver apoio e educação apropriada, pois havendo confiança, comunicação e diálogo aberto, permite-se que os pacientes e seus cuidadores entendam que cada pessoa que o assiste tem uma contribuição significativa em seu processo de recuperação (POPE et al., 2012).

A EB traz consigo modificações que afetam vários sistemas do corpo humano, em especial a epiderme, ocorrendo formações constantes de bolhas, feridas, dor e desconforto na pele. Os pacientes com essa patologia consideram-se 'pessoas borboletas', em função da fragilidade da pele. Para os cuidados contra isso, ressalta-se a promoção da independência e segurança do paciente nas atividades diárias, requerendo modificações no ambiente, tais como o uso de camas especiais, assentos em banheiras, cadeiras de rodas, calçados, entre outros (GROCOTT et al., 2013).

As feridas crônicas da EB são consideradas pelos pacientes como inerentes a eles, já que tentam aceitar a condição de saúde e até mesmo se esforçam para ter uma vida normal, apesar das dificuldades que a doença os impõe. Apesar de tentarem se adaptar aceitando a doença, por vezes os pacientes sentem-se frustrados quando ocorre infecção nas feridas, perda de controle do exsudado ou aumento exagerado no número de feridas (PAUTASSO, 2013).

O tratamento de tais lesões na população com EB apresenta diversos desafios, entre eles a variabilidade clínica para um plano de gestão individualizada, pois a disponibilidade de vários produtos para 
o tratamento das feridas dificulta o processo de decisão, além do grande custo dessas coberturas para o orçamento da família e para as unidades de saúde (WALLY et al., 2013).

Portanto, a avaliação precoce da ferida e o manejo adequado de tratamento são os pilares do cuidado a esses pacientes. A prioridade para pacientes com EB é prevenir a lesão cutânea, já que essa patologia é muito problemática devido à fragilidade da pele. Vestir roupas casuais, por exemplo, podem eventualmente causar a formação de bolhas e levar à formação de feridas (PAPA, 2012).

Por isso, antes de decidir sobre uma estratégia para a gestão dos cuidados de feridas, é importante fazer uma investigação da área de superfície do corpo afetada à procura dos tipos de comprometimento da pele (bolhas intactas, erosões e feridas crônicas). Entretanto, a maioria dos pacientes são muito relutantes em expor sua superfície inteira da pele em cada visita. Muitas vezes, a equipe de cuidado deve negociar um cronograma do exame da pele rotativo, o qual permita que toda a superfície da pele seja cuidadosamente inspecionada pelo menos a cada seis meses. Os sinais de infecção local, como o aumento da vermelhidão, a dor local, o odor e o exsudato, devem ser documentados em cada ferida (FINE, 2015).

\section{CONCLUSÕES}

A EB é uma doença rara, mas quando ocorre, compromete o paciente e pode não apenas provocar péssimos níveis de bem-estar, como também prejudicar consideravelmente a qualidade de vida. Observouse que a dor, o receio quanto ao uso de analgésicos e de utilizar produtos para o cuidado paliativo que tragam resultados significativos, o isolamento social por conta do tempo gasto em curativos e pela não aceitação da autoimagem e a limitação de profissionais especialistas na área, juntos, promovem um ambiente de aflição ao paciente carente de assistência adequada.

Considerando que pacientes com EB, atualmente, ainda não possuem expectativa de cura, a implementação dos cuidados de enfermagem fundamentados em evidências é essencial para promover um melhor estado de saúde aos pacientes, favorecendo melhorias na qualidade de vida não somente do paciente como também do cuidador.

Conclui-se que a enfermagem necessita aprimorar suas práticas para assistir ao paciente com EB. Para isso, é necessário que se encoraje cada vez mais o desenvolvimento de futuras pesquisas que avaliem quais são os melhores curativos e/ou coberturas que auxiliem o paciente. Deve-se desenvolver também treinamento para profissionais generalistas sobre especificidades da EB, bem como para avaliar a dor e os demais cuidados paliativos que podem ser prestados aos pacientes que vivenciam esta condição, pois somente é possível prestar um cuidado de qualidade quando se tem conhecimento acerca de todas as questões que envolvem tanto a doença como o paciente, em seus aspectos físico, social e psicológico.

\section{REFERÊNCIAS}

ADNI, T.; MARTIN, K.; MUDGE, E.. O impacto psicossocial de feridas crônicas em pacientes com epidermólise bolhosa grave. Ferida e Cuidados, v.21, n.11, p.528-538, 2012.
ATKINSON, S.; MCGILLIGAN, V.; LIAO, H.; SZEVERENYI, I.; SMITH, F.; MOORE, C.. Desenvolvimento de siRNA terapêutico alelo-específico para mutações da queratina 5 na epidermólise bolhosa simplex. J Dermatol investigativo, v.131, n.10, p.2079-2086, 2011. 
BRUCKNER-TUDERMAN, L.. Dystrophic Epidermolysis Bullosa: Pathogenesis and Clinical Features. Dermatologic Clinics, v.28, p.107-114, 2010

CUESTA, C.; BLOW, T.; TRANTER, S.. Epidermólise bolhosa: a raro desafio para enfermeiros de diálise peritoneal. Renal Society of Australasia, v.9, n.1, p.41-44, 2013.

DURES, E.; MORRIS, M.; GLEESON, K.; RUMSEY, N.. Você é tudo o que o paciente precisa no momento: o impacto sobre profissionais de saúde e assistência social de apoiar pessoas com epidermólise bolhosa. Doença Crônica, v.6, n.3, p.215227, 2010.

FINE, J.; JOHNSON, L.; WEINER, M.; SUCHINDRAN, C.. Impacto da epidermólise bolhosa herdada nas relações interpessoais dos pais, no estado civil e no tamanho da família. Britanish Journal of Dermatology, v.152, n.5, p.1009-1014, 2015

GROCOTT, P.; BLACKWELL, R.; WEIR, H.; PILLAY, E.. Vivendo em curativos e bandagens: resultados de oficinas com pessoas com epidermólise bolhosa. International Wound Journal, v.1, n.3, p.274-284, 2013.

INTONG, L. R.; MURRELL, D. F.. Inherited epidermolysis bullosa: new diagnostic criteria and classification. Clinics in Dermatologic, v.30, n.1, p.70-77, 2012.

MARGARITA, F.; LECCE, P.; SANTAMATO, W.; VENTURA, P.; SPORTELLI, N.; ANNICCHIARICO, G.. Sintomas e qualidade psiquiátricos de vida em pacientes afetados pela epidermólise bolhosa. Journal of Clinical Psychology Medical Settings, v.17, n.4, p.333-339, 2010.

PAPA, E.; LARA-CORRALES, I.; MELLERIO, J.; MARTINEZ, A.; SCHULTZ, G.; BURRELL, R.. Uma abordagem consensual para o tratamento de feridas na epidermólise bolhosa. Journal of the American Academy of Dermatology, v.67, n.5, p.904917, 2012.

PAUTASSO, M.. Dez regras simples para escrever uma literatura. Biologia Computacional PloS, v.9, n.7, p.1-4, 2013.

SILVA, J. B.; GERHARDT, S.. Epidermólise bolhosa distrófica: aspectos dermatológicos e cirúrgicos. AMRIGS, p.58, n.1, p.65-68, 2014.

SPRECHER, E.. Epidermolysis Bullosa Simplex. Dermatologic Clinics, v.28, p.23-32, 2010.

TOSTI, A.; FARIAS, D. C.; MURRELL, D. F.. Nail involvement in epidermolysis bullosa. Dermatologic Clinics, v.28, n.1, p.153157, 2010.

WALLY, V.; KITZMUELLER, S.; LAGLER, F.; MODER, A.; HITZL, W.; WOLKERSDORFER, M.. Diacereína tópica para epidermólise bolhosa: estudo piloto controlado randomizado. Orphanet Journal of Rare Diseases, v.8, n.1, p.69, 2013.

WRIGHT, J. T.. Oral Manifestations in Epidermolysis Bullosa Spectrum. Dermatologic Clinics, v.28, p.159-164, 2010.

A CBPC - Companhia Brasileira de Produção Científica (CNPJ: 11.221.422/0001-03) detém os direitos materiais desta publicação. Os direitos referem-se à publicação do trabalho em qualquer parte do mundo, incluindo os direitos às renovações, expansões e disseminações da contribuição, bem como outros direitos subsidiários. Todos os trabalhos publicados eletronicamente poderão posteriormente ser publicados em coletâneas impressas sob coordenação da Sustenere Publishing, da Companhia Brasileira de Produção Científica e seus parceiros autorizados. Os (as) autores (as) preservam os direitos autorais, mas não têm permissão para a publicação da contribuição em outro meio, impresso ou digital, em português ou em tradução. 